\title{
Comparative analysis of cancer vaccine settings for the selection of an effective protocol in mice
}

Francesca Kalli ${ }^{1}$, Rodolfo Machiorlatti ${ }^{3}$, Florinda Battaglia' ${ }^{1}$, Alessia Parodi ${ }^{1}$, Giuseppina Conteduca', Francesca Ferrera ${ }^{1}$, Michele Proietti ${ }^{1}$, Samuele Tardito ${ }^{1}$, Marina Sanguineti ${ }^{2}$, Enrico Millo ${ }^{1}$, Daniela Fenoglio ${ }^{1,5}$, Raffaele De Palma ${ }^{4}$, Giorgio Inghirami ${ }^{3}$ and Gilberto Filaci, ${ }^{1,5^{*}}$

\begin{abstract}
Background: Cancer vaccines are considered a promising therapeutic approach. However, their clinical results are not yet satisfactory. This may be due to the the difficulty of selection of an efficient tumor associated antigen (TAA) and immunization protocol. Indeed, the weak antigenicity of many TAA impairs the design of robust procedures, therefore a systematic analysis to identify the most efficient TAA is mandatory. Here, we performed a study to compare different gp100 vaccination strategies to identify the best strategy to provide a 100\% protection against experimental melanoma in a reproducible manner.
\end{abstract}

Methods: C57BL/6J mice were challenged subcutaneously with B16F10 melanoma cells, after vaccination with: a) mouse or human gp100 25-33 peptide plus CpG adjuvant; b) mouse or human gp100 gene; c) mouse or human gp100 $_{25-33}$ peptide-pulsed dendritic cells (DC). Alternatively, a neutralizing anti-IL-10 monoclonal antibody (mAb) was subcutaneously administered at the site of tumor challenge to counteract regulatory cells. Finally, combinatorial treatment was performed associating human gp100 $25-33$ peptide-pulsed DC vaccination with administration of the anti-IL-10 mAb.

Results: Vaccination with human gp100 25-33 peptide-pulsed DC was the most effective immunization protocol, although not achieving a full protection. Administration of the anti-IL-10 mAb showed also a remarkable protective effect, replicated in mice challenged with a different tumor, Anaplastic Large Cell Lymphoma. When immunization with gp100 25-33 peptide-pulsed DC was associated with IL-10 counteraction, a 100\% protective effect was consistently achieved. The analysis on the T-cell tumor infiltrates showed an increase of CD4+granzyme+ T-cells and a decreased number of CD4+CD25+Foxp3+ Treg elements from mice treated with either gp10025-33 peptide-pulsed DC vaccination or anti-IL-10 mAb administration. These data suggest that processes of intratumoral re-balance between effector and regulatory $T$ cell subpopulations may play a critical protective role in immunotherapy protocols.

Conclusions: Here we demonstrate that, in the setting of a cancer vaccine strategy, a comparative analysis of different personalized approaches may favour the unveiling of the most effective protocol. Moreover, our findings suggest that counteraction of IL-10 activity may be critical to revert the intratumoral environment promoting Treg polarization, thus increasing the effects of a vaccination against selected TAA.

\footnotetext{
* Correspondence: gfilaci@unige.it

${ }^{1}$ Centre of Excellence for Biomedical Research, University of Genoa, Viale

Benedetto XV n. 7, 16132, Genoa, Italy

${ }^{5}$ Department of Internal Medicine, University of Genoa, Genoa, Italy

Full list of author information is available at the end of the article
} 


\section{Background}

Cancer immunotherapy is considered a promising therapeutic approach in oncology, and the recent successes obtained by Provenge and Ipilimumab support this view [1-3]. However, despite the discovery of a great number of tumor associated antigens (TAA) [4] and the setting of a large variety of immunotherapy protocols [5], their clinical efficacy remains dismal $[4,6]$. This is likely due to: (a) poor immunostimulatory efficacy of immunotherapy procedures, and (b) escaping mechanisms, as the accumulation of regulatory lymphocytes (Treg) within the tumor environment causing the impairment of anti-tumor cytotoxic cells [7]. Therefore, in presence of a wide array of TAA [8] and a variety of immunotherapy protocols [5], a systematic analysis leading to the identification of reference parameters for the selection and application of each single TAA is mandatory. This is the daunting challenging effort run by the NCI [8] and informative guidelines came from the CIC [9]. Thus, in the setting of an immunotherapy protocol using a specific TAA, a preliminary comparative analysis is recommended in order to identify the most immunogenic strategy able to achieve an optimal antitumor response.

Interleukin 10 (IL-10) is a pleiotropic cytokine secreted by a wide array of immune cells, including monocytes, macrophages, T cells, dendritic cells (DC), B cells, natural killer (NK) cells, mast cells, neutrophilic and eosinophilic granulocytes, and by several tumor cells $[10,11]$. This cytokine signals mainly via STAT3 regulating immunomodulating activities [12]. In particular, it decreases the antigen presenting activity of macrophages and DC mainly through HLA and co-stimulatory molecules down-regulation. Moreover, IL-10 suppresses the production of pro-inflammatory cytokines (i.e. IL-1 $\alpha$, IL$1 \beta$, TNF- $\alpha$, IL-6, IL-8, IL-12, IL-18, granulocyte-macrophage colony-stimulating factor [GM-CSF], macrophage inflammatory protein-1, RANTES, leukemia inhibiting factor, IFN $\gamma$ ), and inhibits nuclear translocation of NF$\mathrm{kB}[13,14]$. At the same time, this cytokine is a NK cell activator [15] and a co-stimulator of mast cell proliferation $[16,17]$. Finally, IL-10 promotes B lymphocyte differentiation and immunoglobulin production [18], and plays a relevant role in immune regulation, mediating the activity of different regulatory $\mathrm{T}$ cell (Treg) subsets [19-21]. This pivotal role, associated with the finding that the tumor environment is usually rich in IL-10 secreted by tumor cells [22,23] and/or by tumor infiltrating elements [24], suggests that this cytokine has a critical function in tumor immune escaping. Thus, the inhibition of IL-10 has been proposed as a useful strategy in anti-cancer therapy $[25,26]$.

In this study, we focused on a single TAA, gp100, in an established melanoma model, analyzing different gp100 centred vaccination strategies. Our main aim was to identify a protocol able to consistently provide $100 \%$ tumor protection, and this aim was achieved only when the most efficacious effector strategy was associated with IL-10 blockade to counteract Treg activity.

\section{Materials and methods \\ Cell lines}

The cell lines used in this study were: a) B16F10 melanoma cells (a spontaneous C57BL/6J-derived melanoma widely used for the evaluation of therapy [27]); b) RMA/ $\mathrm{S}$ cells, a murine T-lymphoma cell line deficient in the presentation of endogenously synthesized antigens by MHC class I molecules [28] (kindly provided by Dr. G. Pietra from the Advanced Biotechnology Center of Genoa); c) VAC cell line, which is an immortalized line from primary lymphoma derived from a NPMALKtransgenic mouse backcrossed onto the BALB/c background (CD4+/ALK+ lymphoblastic lymphoma) [29], and used for generating syngenic s.c. tumorgrafts of Anaplastic Large Cell Lymphoma (ALCL).

All lines were cultured in RPMI 1640 medium (GIBCO, Life Technologies Ltd., Paisley, UK) containing 10\% heatinactivated fetal bovine serum (FCS, Euroclone, Wetherby, $\mathrm{UK}), 2 \mathrm{mM} / \mathrm{L}$ L-glutamine, $100 \mathrm{U} / \mathrm{ml}$ penicillin, $100 \mu \mathrm{g} / \mathrm{ml}$ streptomycin (GIBCO) in a humidified atmosphere at $37^{\circ} \mathrm{C}$ and $5 \% \mathrm{CO}_{2}$.

\section{Mice}

C57BL/6J, 6- to 8-week old, female mice were purchased from Harlan Laboratories (S.Pietro al Natisone, Udine, Italy). BALB/c mice were purchased from Charles River Laboratories (Calco, Lecco, Italy).

Animal procedures were conducted in accordance with the institutional guidelines and experiments have been reviewed and approved by Ethics Committee for Experimentation on Animals (CSEA) of Genoa and Turin.

\section{Synthesis of the highly immunogenic peptide} encompassing residues 25-33 of mouse and human gp100 Mouse (EGSRNQDWL) and human (KVPRNQDWL) gp100 $25-33$ peptides, as well as influenza virus nucleoprotein $\mathrm{A} \mathrm{NP}$ 366-374 (ASNENMETM) peptide, were in house synthesized at the biochemical facility of the Centre of Excellence for Biomedical Research by standard methods of solid phase peptide synthesis, which follows a 9-fluorenylmethoxycarbonyl (Fmoc) strategy with minor modifications [30]. Synthesized compounds were purified by reverse-phase high performance liquid chromatography (HPLC) and molecular weights confirmed by electrospray ion-trap mass spectrometry. The purification of individual compounds was obtained on a Shimadzu LC-9A preparative HPLC (Shimadzu, Kyoto, 
Japan) equipped with a Waters C18 $\mu$ Bondapack column (19 x 300 mm; Waters, Milford, MA).

\section{Culture of bone marrow derived DC and activation for the expression of gp100 on its surface}

Bone marrow (BM) derived DC were generated as described [31]. BM cells were harvested from thigh-bones and tibias of naïve C57BL/6J mice and washed with phosphate-buffered saline (PBS) (Invitrogen, Life Technologies). Cells $\left(1 \times 10^{6} / \mathrm{ml}\right)$ were suspended in DC medium consisting in RPMI 1640 supplemented with 10\% heat-inactivated FCS (HyClone, Logan, UT), $2 \mathrm{mM}$ L-glutamine, $100 \mathrm{U} / \mathrm{ml}$ penicillin, $100 \mu \mathrm{g} / \mathrm{ml}$ streptomycin, $100 \mathrm{mM}$ sodium pyruvate, $10 \mathrm{mM}$ Hepes buffer solution, $100 \mathrm{mM}$ non essential amino acids solution, $50 \mu \mathrm{M} \beta$-mercaptoetanol (GIBCO), and plated plate with $20 \mathrm{ng} / \mathrm{ml}$ murine GM-CSF (6 well plates, PeproTech, Rocky Hill, NJ). On day 3, fresh medium was added plus $5 \mathrm{ng} / \mathrm{ml}$ murine GM-CSF (PeproTech). On day 7, the DC phenotype was checked using the following mAbs: fluorescein isothiocyanate (FITC) conjugated anti-MHC class II (HLA DR), phycoerythrin (Pe) cyanin 7 conjugated anti-CD11c, allophycocyanin (APC) conjugated anti-CD86 (Biolegend, San Diego, CA). More than 90\% of the cells showed high expression of all DC markers. Before administering DC to animals, DC $\left(1 \times 10^{6} / \mathrm{ml}\right)$ were activated with CpG $(1 \mu \mathrm{g} / \mathrm{ml})$ for 8 hours; then, activated DC $\left(2 \times 10^{6} / \mathrm{ml}\right)$ were pulsed by incubation with mouse or human gp $100_{25-33}$ peptide $(2 \mu \mathrm{M})$ at $37^{\circ} \mathrm{C}$ for 2 hours.

\section{gp100 vaccination of C57BL/6J mice against B16F10 melanoma}

In vivo experiments were performed analyzing at least 5 animals per group; each experiment was repeated for 3 times.

C57BL/6J mice were immunized against gp100 molecule following three different protocols: 1) peptide plus adjuvant; 2) gene immunization; 3) peptide-pulsed DC immunization (summarized in Additional file 1: Figure S1 in Additional files). Peptides plus adjuvant protocol: peptides were administered by injecting subcutaneously either mouse $\left(\mathrm{mgp} 100_{25-33}\right)$ or human (hgp100 $\left.25-33\right)$ gp $100_{25-33}$ preparations $(100 \mu \mathrm{g} /$ mouse) in association with CpG $(30 \mu \mathrm{g} / \mathrm{mouse})$, as adjuvant. The unrelated $\mathrm{NP}_{366-374}$ peptide from influenza virus nucleprotein $\mathrm{A}$ was used as negative control in preliminary experiments. Gene immunization: this protocol was executed administering intramuscularly plasmids expressing either mouse or human gp100 gene sequence $(100 \mu \mathrm{g} / \mathrm{mouse})$. A pCMVscript plasmid (Stratagene) was used as gene vector. The gene coding for mouse gp100 molecule was amplified from cDNA obtained after extraction of RNAs from B16F10 melanoma cells. The construct coding for human gp100 was kindly provided by Prof. N. Restifo
(NIH, Bethesda). PCR amplified products were first cloned into a sequencing vector (TOPO TA cloning from Invitrogen) and then Sanger sequenced. Both mouse and human gp100 cloned genes were subsequently transferred in the eukaryotic expressing vector pCMVscript.The empty pCMVscript plasmid was used as negative control in preliminary experiments. Peptidepulsed DC immunization: this protocol was performed injecting in the right flank DC $\left(2 \times 10^{6} /\right.$ mouse $)$ pulsed with either mouse or human gp $100_{25-33}$ peptide. Unpulsed DC or DC pulsed with the unrelated $\mathrm{NP}_{366-374}$ peptide were used as negative control in preliminary experiments. The schedule of each protocol consisted in three immunizations, administered weekly. At the time of the third immunization, mice received the tumor challenge, that consisted in sc. injection in the controlateral limb of B16F10 cells $\left(1 \times 10^{5}\right.$ cells/mouse). Tumor masses were measured with calipers at 2-3 days intervals by measuring long and short axes. Area was calculated according to the formula: tumor area $=$ length $\times$ width in $\mathrm{mm}^{2}$. Mice were sacrificed when tumors reached $>100 \mathrm{~mm}^{2}$ or when ulceration and/or bleeding developed.

\section{Immunotherapy of B16F10 melanoma in C57BL/6J mice or ALCL in BALB/C mice based on IL-10 neutralization} In vivo experiments were performed analyzing 5 animals per group; each experiment has been repeated 3 times.

C57BL/6J were s.c. challenged with B16F10 melanoma ( $1 \times 10^{5}$ cells/mouse) while BALB/c mice were injected s.c. withVAC $\left(1 \times 10^{6}\right.$ cells/mouse $)$ cells. The neutralizing anti-IL-10 (Anti-Mouse IL-10 Functional Grade Purified, clone JES5-16E3) (eBioscience, San Diego, CA) mAb $(150 \mu \mathrm{g} / \mathrm{mouse})$ was administered subcutaneously at the site of tumor challenge immediately after tumor cell injection as well as after one and two weeks from baseline. A rat IgG2b,k control isotypic antibody (Biolegend, San Diego, CA) was administered using the identical schedule adopted for the anti-IL10 mAb. When IL-10 blockade was associated in combinatorial treatment to gp100 vaccination, the neutralizing anti-IL-10 mAb $(150 \mu \mathrm{g} / \mathrm{mouse})$, or its isotypic control, were subcutaneously administered as described above.

\section{Purification of splenocytes and intratumor lymphocytes}

Spleens or tumors, removed from sacrificed mice, were minced with a sharp sterile blade, placed in a 40- $\mu \mathrm{m}$ nylon cell strainer (BD Biosciences, Franklin Lakes, NJ), and pressed with the plunger of a syringe until cellular elements were released. Red blood cells were lysed with red blood cell lysing buffer (Sygma Aldrich), and washed. Tumor or splenocyte suspensions were collected in RPMI 1640 medium supplemented with 10\% FCS. Splenocytes from treated and untreated mice $\left(2.5 \times 10^{6} / \mathrm{ml}\right)$ were plated in flasks in the presence of irradiated (3000 rad) 
splenocytes $\left(1 \times 10^{6} / \mathrm{ml}\right)$ and gp $100_{25-33}$ peptide $(10 \mu \mathrm{g} / \mathrm{ml})$ and cultured for 5 days. After incubation, splenocytes were collected and separated by density gradient (Biochrom AG, Berlin, Germany). Splenocyte samples were used for phenotypical analysis, the remaining portion for ELISPOT assay.

In the ALCL model, we applied two overnight incubations with ALK inhibitor CEP28122 $(20 \mathrm{ng} / \mathrm{ml})$ followed by separation by density gradient before phenotype analysis.

Immunofluorescence and flow cytometric (FACS) analysis Phenotypes of tumor infiltrating $\mathrm{T}$ lymphocytes (TIL) and whole splenocytes were analyzed by immunofluorescence incubating the cells $\left(1 \times 10^{5}\right.$ lymphocytes in $100 \mu \mathrm{l}$ of PBS) with specific $\mathrm{mAbs}$ at $4^{\circ} \mathrm{C}$ for 30 minutes in the dark. The following mAbs were used: FITC conjugated anti-GranzymeB (eBioscience), Pe-conjugated anti-Foxp3 (eBioscience), Peridinin chlorophyl protein (PerCP)-cyanin 5.5-conjugated anti-CD8 (Biolegend), anti-CD28(Biolegend), PeCy 7-conjugated anti-CD3 (BD Pharmingen), APC-conjugated anti- (BD Pharmingen), APCCy 7-conjugated anti-CD4 (BD Pharmingen). For intracellular staining, cells were permeabilized and fixed using FOXP3 Fix/Perm Buffer Set (Biolegend) according to manufacturer's instructions and then incubated with fluorochrome conjugated anti-GranzymeB and antiFoxp3mAb; fluorochrome-conjugated isotype matched Abs were also used as controls. After the staining, the analysis was performed by flow cytometry using a FACSCanto II flow cytometer equipped with FACS Diva software (BD).

\section{Elispot assay}

Detection of IFN $\gamma$ production by splenocytes in response to peptide stimulation was carried out using an enzymelinked immunospot (Elispot) assay (Millipore, Merck KGaA, Darmstadt, Germany) according to the manufacturer's instructions. Briefly, splenocytes $\left(2 \times 10^{5} /\right.$ well $)$ from treated and untreated mice, cultured for 5 days with irradiated splenocytes plus peptide $(10 \mu \mathrm{g} / \mathrm{ml})$ were harvested, and dead cells were removed by centrifugation on density gradient (Biochrom). Then, cells were collected and washed before incubating them overnight at $37^{\circ} \mathrm{C}$ with either mgp $100_{25-33^{-}}$or hgp $100_{25-33}$-pulsed RMA/S cells $\left(1 \times 10^{4}\right.$ cells $)$ in 96 -well plates coated with $10 \mu \mathrm{g} / \mathrm{ml}$ of unlabeled anti-mouse IFN $\gamma$ rat monoclonal capture antibody (clone AN18, Millipore). At the end of incubation, a biotinylated detection antibody $(2 \mu \mathrm{g} / \mathrm{ml})$ was added to the wells and reacted with alkaline phosphatase-streptavidin (100 $\mu \mathrm{l} /$ well $)$ and the development with BCIP/NBT Phosphatase substrate $(50 \mu \mathrm{l} /$ well) (KPL, Kirkegaard \& Perry Laboratories, Inc.). Frequencies of IFNy producing cells were measured using a BioReader 3000 Elispot Reader (Bio-Sys $\mathrm{GmbH}$ ). Data are expressed as the mean number of spots per duplicate.

\section{Proliferation inhibition assay}

The suppression activity was evaluated by monitoring the proliferation of splenocytes isolated from C57BL/6J and from BALB/c mice by dye dilution approach. For this assay, splenocytes (used as responder cells) were stained with carboxyfluorescein succinimidyl ester (CFSE) $5 \mu \mathrm{M}$ (Molecular Probes, Life Technologies) and co-cultured with Concanavalin A (Con A) (Sigma Aldrich) at $5 \mu \mathrm{g} / \mathrm{ml}$ for 5 days in a 96 well flat bottomed plate with or without tumor infiltrating lymphocytes (TIL) from melanoma or lymphoma tumors (used as suppressor cells). Splenocytes:TIL cell ratio was 2:1. Co-cultures with TIL from both tumors were also performed in the presence or absence of the neutralizing anti-IL-10 $\mathrm{mAb}$ (clone JES5-16E3 eBioscience) $(10 \mu \mathrm{g} / \mathrm{ml})$ or of its isotypic control. After 5 days the cultures were washed in PBS and acquired by FACS Canto flow cytometer equipped with FACS Diva software (Becton Dickinson, BD). A total of 50000 CFSE positive responder cells were analyzed. The results were expressed as percentage of CFSE bright splenocytes.

\section{Immuno-histochemical analysis}

Tumors specimens were taken from either anti-IL-10 mAb treated mice or controls and fixed with nitrogen vapors. Tissue sections, obtained from melanoma specimens, were stained with monoclonal antibody against IL-10 (Purified Rat anti-mouse IL-10, clone JES5-16E3, BD, Milano, Italy) following the manufacturers' instructions.

\section{Statistical analysis}

Comparisons between mean values were performed by unpaired or paired t test using the Graph-Pad Prism 5.0 software (Graph-Pad Software, Inc, San Diego, CA, USA). Data were considered statistically significant when $p \leq 0.05$.

\section{Results}

Comparative analysis of protective effect among protocols inducing anti-cancer effector immune responses

Our studies wanted to compare different strategies of vaccination. Since each of these strategies would require specific controls, we preliminarly performed an analysis of the effects of each control on tumor growth. The controls were: a) s.c. immunization with the $\mathrm{NP}_{147-155}$ gp100 unrelated peptide plus CpG adjuvant; b) i.m. administration of the empty pCMVscript plasmid; c) s.c. administration of DC unpulsed or pulsed with the $\mathrm{NP}_{147-155}$ gp100 unrelated peptide. Additional 1: FigureS2 shows that in repeated experiments none of these procedures significantly modified tumor growth. Based on these data, in order to have a unique, homogeneous control for all the experiments we performed the following 
studies using spontaneous tumor growth as universal control.

In a syngeneic setting gp100 $25-33$ peptide-pulsed DC vaccination was the most effective, inducing $>50 \%$ tumor mass reduction, while peptide vaccination and gene vaccination had comparable efficacies (Figure 1A). According to the protection results, mice treated with peptide-pulsed DC had among splenocytes a significantly higher frequency of IFN $\gamma$-secreting $\mathrm{T}$ cells in response to gp100 25 -33 peptide stimulation than control animals (Figure 1B), as assessed by Elispot analysis.

These experiments were repeated in a xenogeneic setting, using the human gp100 25 -33 peptide or a plasmid coding the human gp100 protein. In this setting, vaccination with DC pulsed with the gp100 $25-33$ peptide remained the most effective protocol, although peptide plus adjuvant vaccination achieved comparable results (Figure 2A).

The Elispot analysis of frequency of IFNy-secreting $\mathrm{T}$ splenocytes in response to gp $100_{25-33}$ peptide showed a higher number of positive cells versus controls, in all groups of treated mice (Figure 2B).

These data clearly indicate that the protocol with gp $100_{25-33}$ peptide-pulsed DC was the most effective strategy. To verify which protocol between the syngeneic and the xenogeneic setting could produce the most
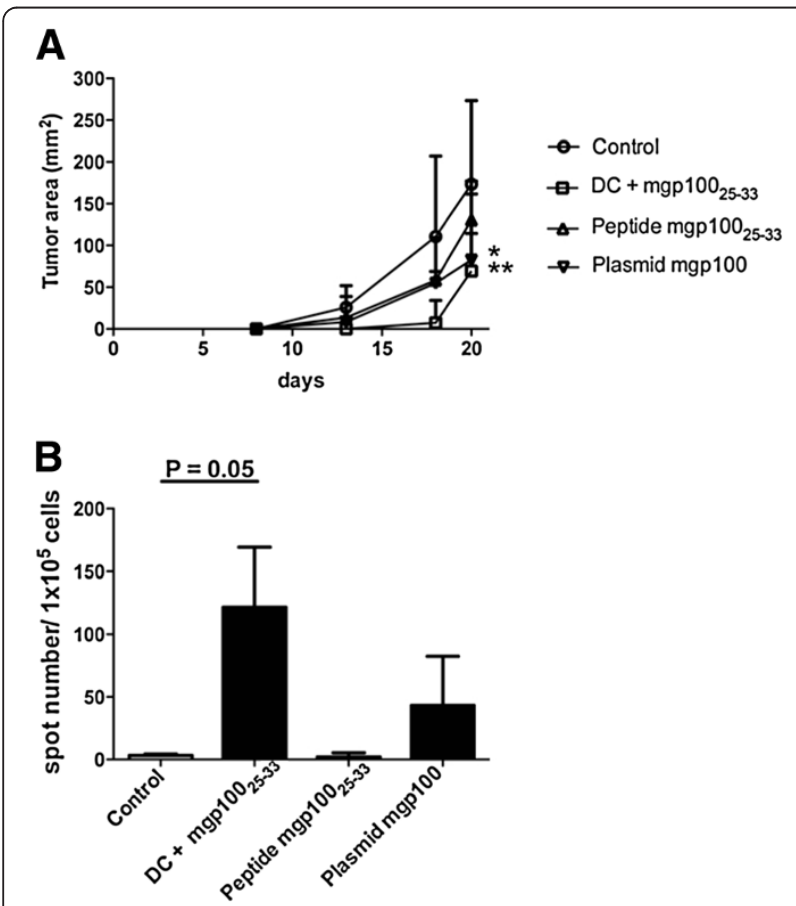

Figure 1 Comparative analysis of the different gp100 vaccination protocols in a syngeneic setting. (A) B16F10 melanoma growth curves in differently treated and control mice $\left({ }^{*} p=0.05 ;{ }^{* *} p=0.01\right)$; (B) Elispot analysis of frequency of IFNy-secreting splenocytes from differently treated and control mice.
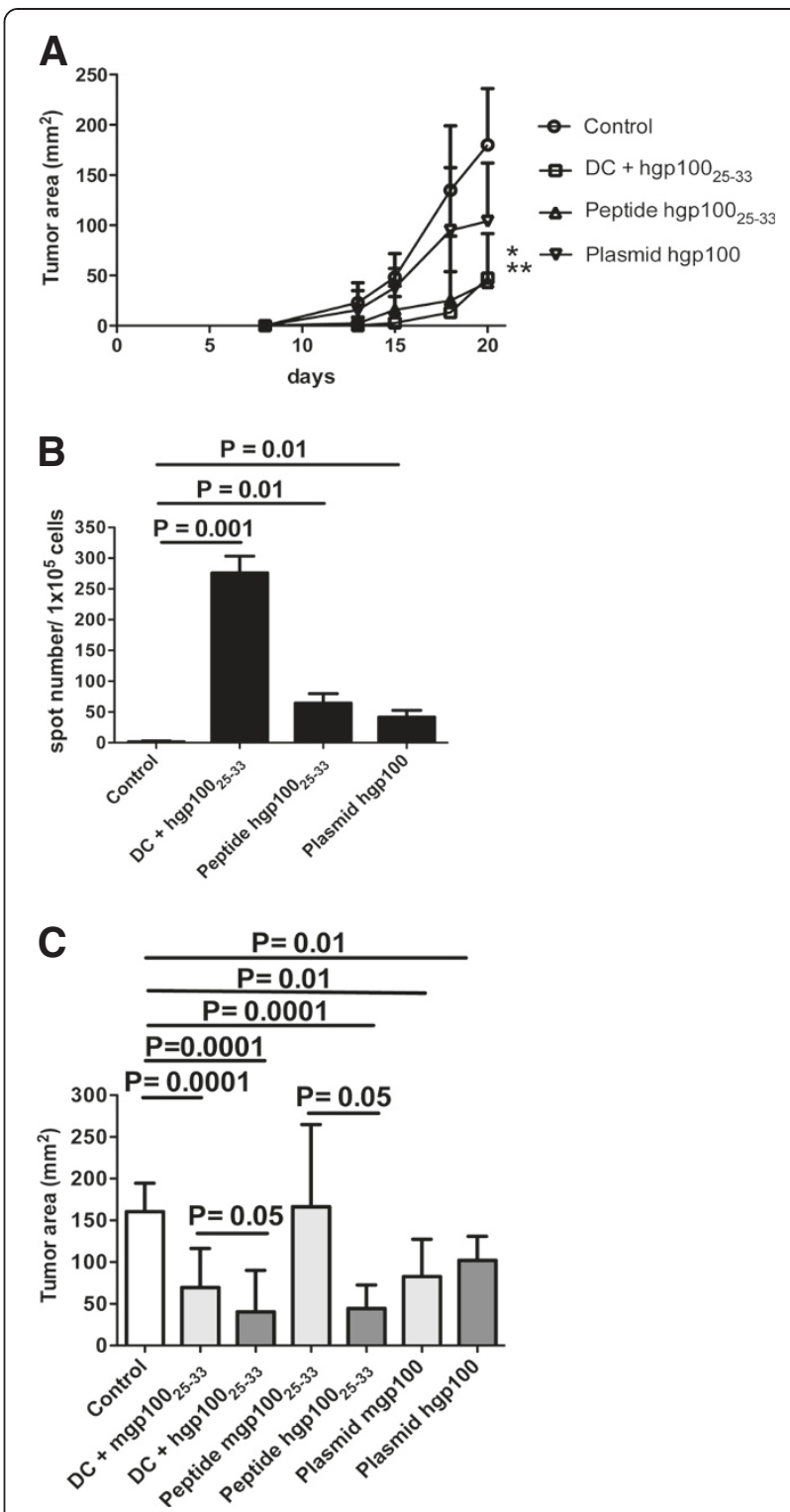

Figure 2 Comparison of gp100 vaccination protocols performed either in syngeneic or xenogeneic setting. (A) Comparative analysis of the different gp100 vaccination protocols in a xenogeneic setting. B16F10 melanoma growth curves in differently treated and control mice $\left({ }^{*} p=0.05 ;{ }^{* *} p=0.01\right)$; (B) Elispot analysis of frequency of IFNY-secreting splenocytes from differently treated and control mice in a xenogeneic setting; (C) Comparison of gp100 vaccination protocols performed in syngeneic (light grey columns) or xenogeneic (dark grey columns) settings. Data refer to the assessment performed after 21 days from B16F10 melanoma challenge when mice were sacrificed.

protective action against tumor growth, we combined all data and compared them. Figure $2 \mathrm{C}$ shows that vaccination performed with the human gp $100_{25-33}$ peptide was able to reduce melanoma growth more than the vaccination performed with the mouse corresponding peptide. 


\section{Analysis of effector and regulatory $\mathrm{T}$ cells in mice vaccinated with gp100 25 -33 peptide-pulsed DC}

To understand the cellular mechanisms underlying the effects of pulsed DC vaccination, the frequencies of CD4+ granzyme+ and CD8+granzyme+ T cells (representative of effector $\mathrm{T}$ cell populations) and of CD4+CD25+FoxP3+ Treg (representative of regulatory lymphocytes) were analyzed in spleens and in tumors from treated and untreated mice. Figure 3A shows that the frequency of $\mathrm{CD} 4+$ granzyme+ $\mathrm{T}$ cells in treated mice was significantly higher than in controls both in spleens and in the host tumor microenvironment. No significant variations were observed in the CD8+granzyme+ $\mathrm{T}$ cell compartment (not shown). Moreover, a decrease of CD4+CD25+Foxp3+ Treg was observed in treated mice with respect to untreated controls in the tumors but not in the spleen (Figure 3B).

Protective effect of IL-10 neutralization against melanoma and ALCL growth

Since none of the immunization protocols exerted a complete protection against B16F10 melanoma engrafting, we hypothesized that a specific counteraction of the

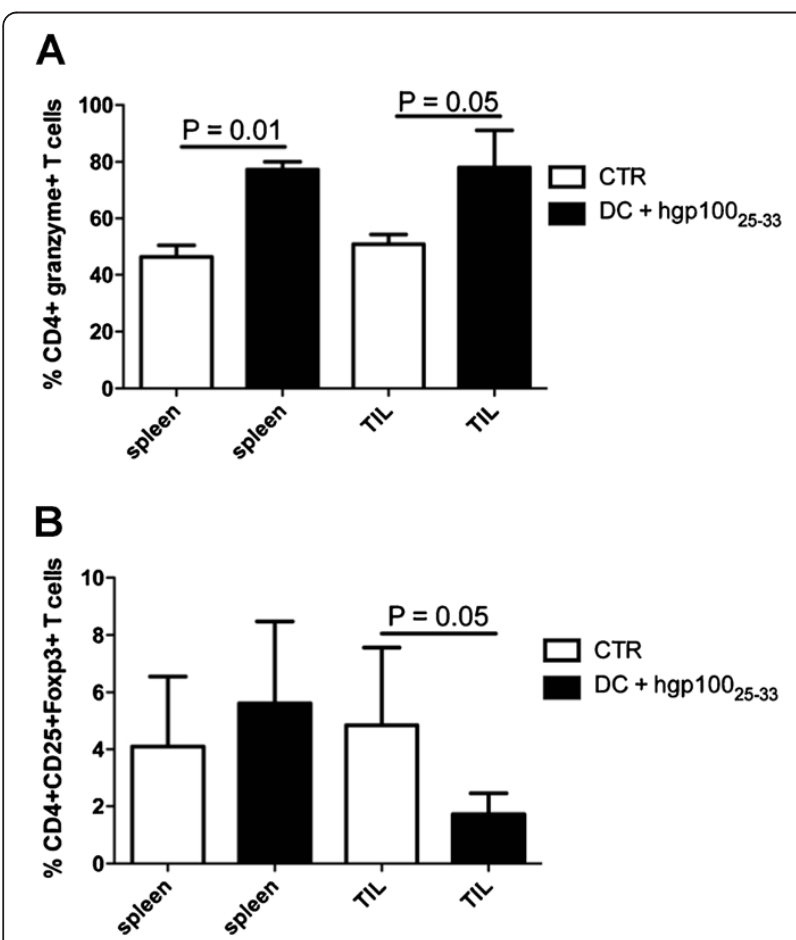

Figure 3 Frequency of CD4+granzyme+ and CD4+CD25+Foxp3+ T lymphocytes in vaccinated mice. FACS analyses of frequency of CD4+granzyme+ (A) and CD4+CD25+Foxp3+ (B) T lymphocytes were performed in mice immunized or not with gp100 $25-33$ peptide-pulsed DC. The analyses were executed on splenocytes and TIL from immunized (black columns) or untreated (white columns) mice. Data in both panels are expressed as percentage of positive cells out of the total $\mathrm{CD} 3+\mathrm{T}$ cell population. regulatory $\mathrm{T}$ cell compartment could increase the efficiency of spontaneous and/or vaccine induced anti-tumor effector mechanisms. This hypothesis was supported by the data generated using Ipilimumab in human protocols $[1,32]$. Indeed, the observation that TIL purified from melanoma lesions exerted a regulatory activity in an IL-10 dependent fashion confirmed this idea (Figure 4A). Moreover, melanoma sections stained with an anti-IL-10 mAb demonstrated the presence of the cytokine in the tumor microenvironment (data not shown).

Hence, we decided to verify whether in vivo IL-10 neutralization could represent a useful mean for counteracting the activity of the regulatory $\mathrm{T}$ cell compartment.

Indeed, IL-10 blockade by an anti-IL- $10 \mathrm{mAb}$, administered in monotherapy at the site of tumor challenge, led to a significant delay in melanoma growth, reminiscent of what observed in different experimental settings [33] (Figure 4B). Importantly, the same anti-IL-10 mAb added in vitro $(20 \mu \mathrm{g} / \mathrm{ml})$ to B16/F10 melanoma cell culture did not change either cell proliferation rate or cell viability, ruling out the possibility of any direct toxic effect (not shown).

In order to understand whether the effects mediated by IL-10 neutralization were melanoma-specific or could be replicated in a different unrelated type of tumor, the same experiment was performed using mouse anaplastic large cell lymphoma (ALCL) cells (ALK+ VAC cells, [29]) as challenging tumor. Preliminarly, the IL-10-dependent regulatory activity exerted by TIL was also demonstrated for this model (Figure 4C). Indeed, in vivo IL-10 blockade resulted in a significant protection against ALCL growth (Figure 4D).

In the attempt to understand the mechanisms responsible for the protective effect of IL-10 blockade, phenotypic analyses were performed on TIL of mice treated with the neutralizing anti-IL-10 mAb. These analyses showed that in both tumor microenvironments, IL-10 treatment caused a significant increase of CD4+granzyme+ $\mathrm{T}$ cells with a concomitant decrease of CD4+CD25+FoxP3+ Treg, reminiscent of what observed after vaccination with $\mathrm{gp} 100_{25-33}$ peptide-pulsed DC (Figure 5). No changes in the percentage of either CD4+granzyme+ $\mathrm{T}$ cells or $\mathrm{CD} 4+$ CD25+FoxP3+ Treg were observed in splenocytes when we compared treated and untreated mice (not shown).

Based on these results, we arrived to the conclusion that a combinatorial treatment associating Treg counteraction, through IL-10 blockade, with stimulation of the anti-tumor immune response, through vaccination, could have addictive/synergic efficacy. Accordingly, the combinatorial administration of the anti-IL10 mAb, but not its related isotypic control (not shown), to gp100 $25-33$ peptide-pulsed DC vaccinated mice led to a complete protection from B16F10 melanoma growth (Figure 6). 

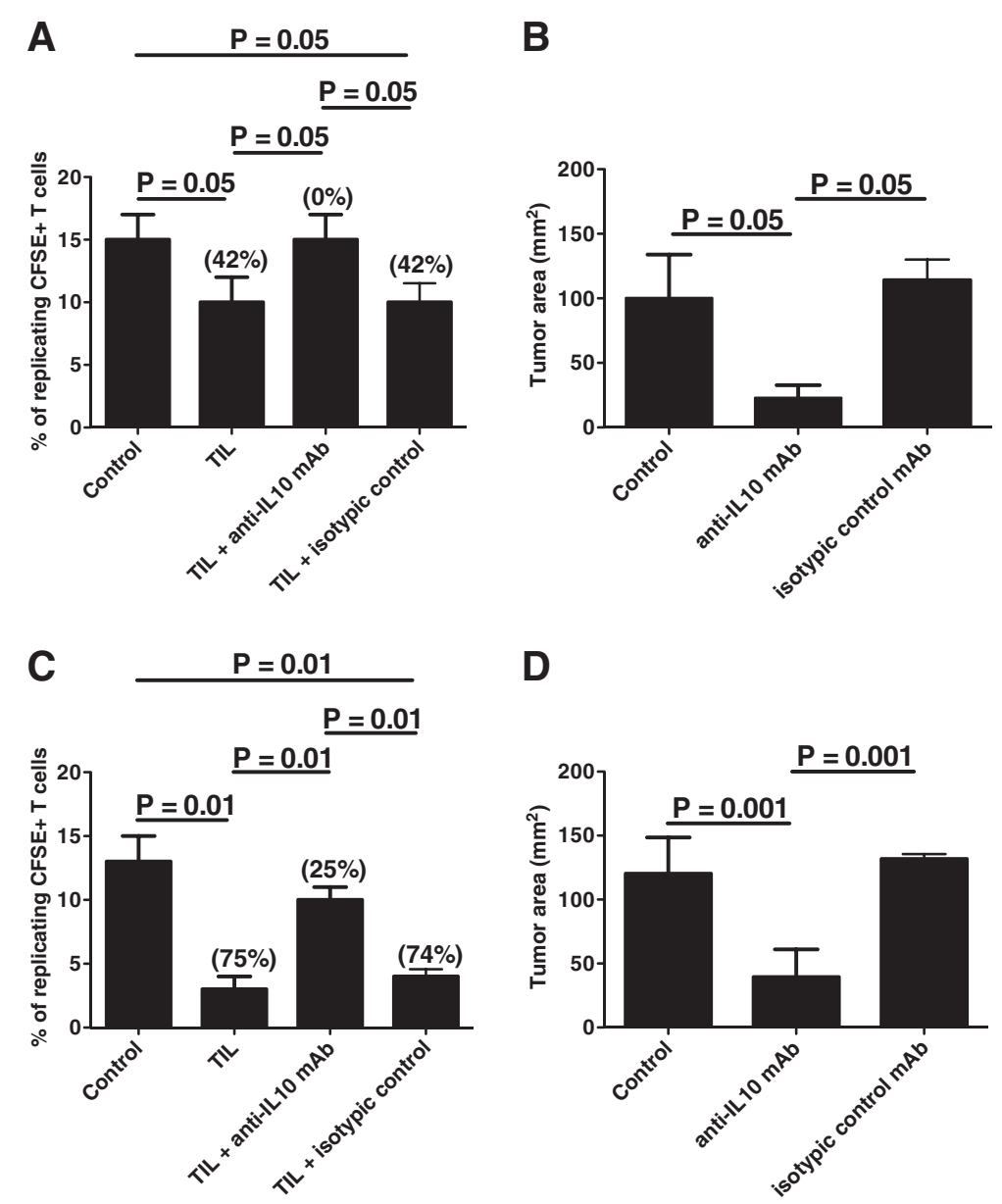

Figure 4 Involvement of IL-10 in tumor growth. (A and C) Suppression assay performed with TIL purified from melanoma (A) or ALCL (C). CFSE-labeled syngeneic splenocytes were in vitro stimulated with Con A and co-incubated with TIL in the presence or not of an anti-IL-10 mAb or its relative isotypic control. Data are expressed as percentage of replicating, CFSE+ cells; percentage of inhibition are indicated in parentheses. (B and D) Mean tumor dimensions in mice challenged after 21 days with either B16F10 melanoma (B) or VAC ALCL (D) cells and treated or not with an anti-IL-10 mAb or its relative isotypic control.

\section{Discussion}

Our data demonstrate that: a) the vaccination with DC pulsed with gp100 $25-33$ peptide was the most effective in protecting C57BL/6 mice from B16F10 melanoma development compared to other gp100 vaccination protocols such as peptide plus adjuvant or gene vaccination; b) different protective effects were observed in syngeneic or xenogeneic settings in gp100 peptide-centred cancer vaccination protocols; c) the protective effects exerted by $D C$ vaccination were related to increased intratumoral concentration of granzyme $+\mathrm{CD} 4+\mathrm{T}$ cells and decreased concentration of CD4+CD25+Foxp3+ Treg; d) counteraction of IL-10 by a neutralizing mAb lowered the rate of tumor development, inducing an increase of intratumoral concentration of granzyme $+\mathrm{CD} 4+\mathrm{T}$ cells and a decrease of CD4+CD25+Foxp3+ Treg; e) only the combinatorial treatment associating $\mathrm{DC}$ vaccination with
IL-10 blockade was able to abrogate completely tumor growth.

Cancer vaccination is based on the identification at the molecular level of antigens expressed preferentially by specific tumors. Although Sipuleucel-T is the first cancer vaccine that recently reached the clinic after receiving the authorization for clinical use in prostate cancer [34], it is believed that immunological protocols will reach a full clinical efficacy and wide application in oncology only when well defined oncoantigens will be proved efficient by in vivo protective experiments. Hence, this process requires a systematic analysis of the protective effect of the different TAA and related protocols of administration, since several variables, including type of antigen, route of administration, molecular form of antigen administration, selection of adjuvants, may condition the outcome of the treatment [35]. In this 


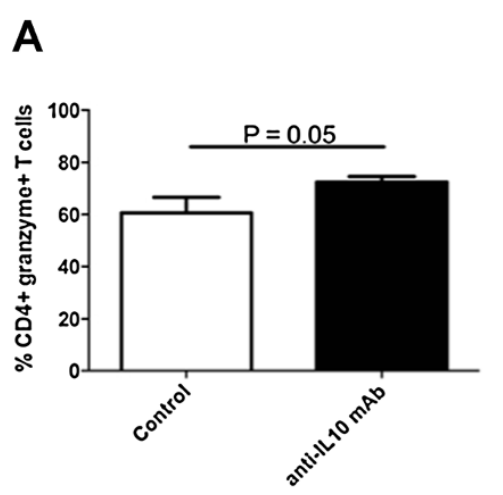

B
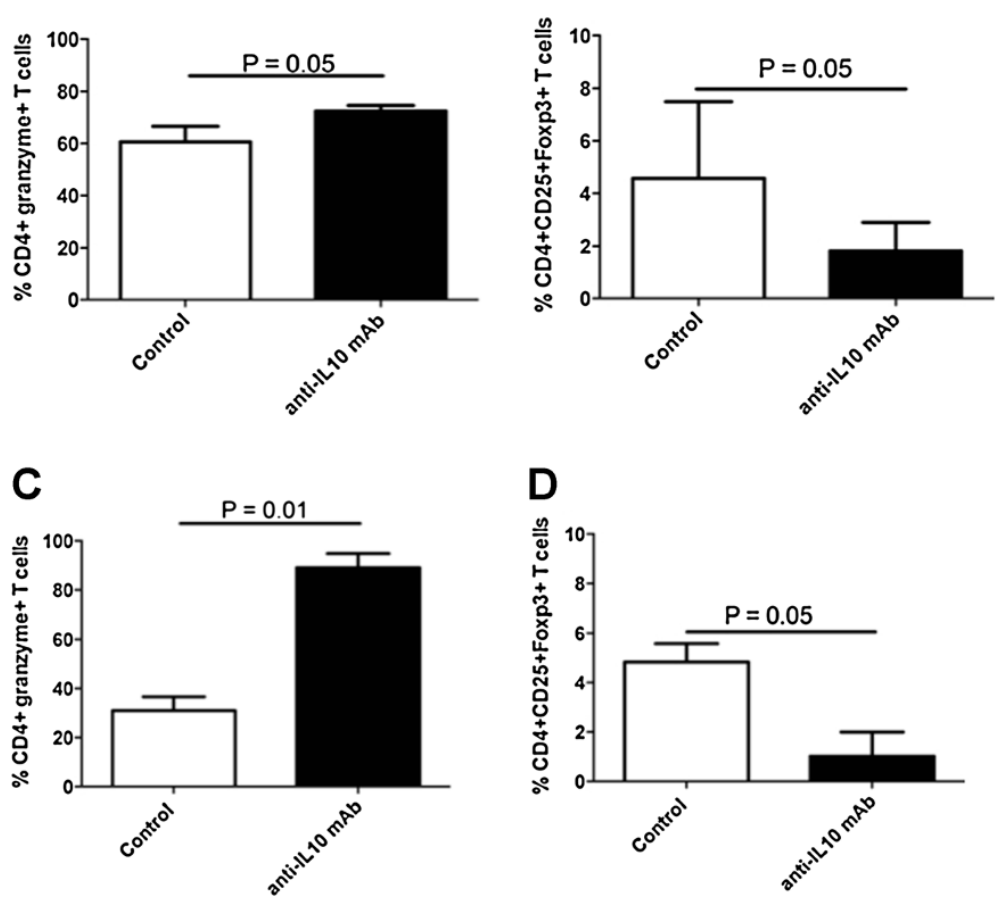

Figure 5 Frequency of CD4+granzyme+ and CD4+CD25+Foxp3+ T lymphocytes in mice treated with an anti-IL-10 mAb. FACS analyses of frequency of CD4+granzyme+ (A and $\mathbf{C}$ ) and CD4+CD25+Foxp3+ (B and $\mathbf{D})$ T lymphocytes were performed in mice untreated or treated with an anti-IL-10 mAb. The analyses were executed on TIL from treated (black columns) or untreated (white columns) mice. (A) and (B) panels refer to experiments performed in C57BL/6J mice challenged with B16F10 melanoma cells; (C) and (D) panels refer to experiments performed in Balb/C mice challenged with VAC ALCL cells. In all panels, data are expressed as percentage of positive cells out of the total CD3+ T cell population.

paper, we compare the protective efficacy of different protocols of cancer vaccination based on a classical, widely adopted model system constituted by gp100 vaccination in B16F10 melanoma [27]. Intriguingly, the comparison of different vaccination protocols, such as peptide plus adjuvant, gene immunization and peptide-pulsed DC immunization, showed different levels of protective efficacy among the three protocols, being DC vaccination the most effective one. This is a remarkable observation since suggests that adequate stimulation of a single (or limited number of) $\mathrm{T}$ cell clone(s), specific for one specific TAA epitope, as induced by peptide-pulsed DC vaccination, may have more pronounced protective effects than multiepitope mediated stimulation of a wide TAA-specific T cell repertoire, as induced by vaccination with a gene coding for the entire TAA molecule. Importantly, the protective effects of identical protocols performed in syngeneic or xenogeneic settings differed greatly. This is not surprising since the efficacy of xenogeneic immunization has been already reported in different models of experimental tumor and associated with the expression of a heteroclitic epitope by the immunizing agent [36,37]. The use of xenogeneic or modified tumor antigens, as a system for increasing the immunogenicity of the vaccine and breaking tolerance, has been suggested for long time [4,38]. However recent evidences from human trials seems to disprove the efficacy of this approach [39]. Taken together, data reported here further demonstrate the need of experimental testing to assess the most efficient protocols. Indeed, our analyses deserve to be replicated in different tumor model systems in order to verify whether our findings represent a generalized phenomenon in cancer vaccination.

The protective effect exerted by a cancer vaccination protocol is likely related to a number of biological factors concerning the immunogenicity of the antigen, the competence of the $\mathrm{T}$ and $\mathrm{B}$ cell repertoires, the level of activation of innate immunity, the capacity of the antigen to elicit immune responses involving a wide scenario of lymphocyte subtypes ( $\mathrm{T}$ helper, CTL, Th17, B lymphocytes) and, last but not least, the number of boosts [40-44]. Hence, monitoring cancer vaccine-induced immune response, should take into consideration a variety of factors, likely becoming an impossible challenge for clinical trials.

Trying to simplify what underlies complex biological networks, the outcome of an immune response may be function of the ratio between the effector and the regulatory response [45-47]. In this study, we selected the 

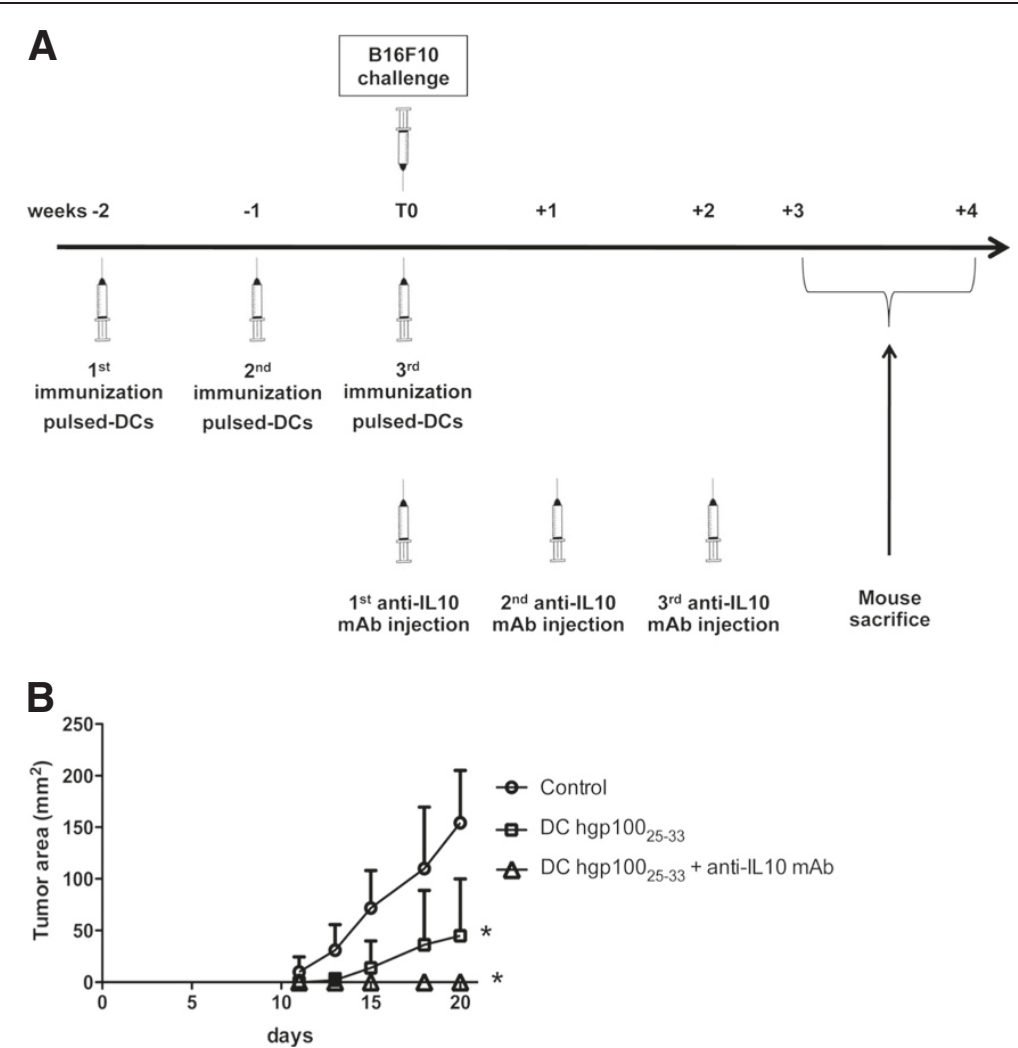

Figure 6 Combinatorial treatment of B16F10 melanoma: vaccination with gp $100_{25-33}$ pulsed-DC plus neutralizing anti-IL-10 mAb administration. (A) Schedule of treatment; (B) B16F10 melanoma growth curves in differently treated and control C57BL/6J mice $\left({ }^{*} \mathrm{P}=0.05\right)$.

intratumoral concentration of granzyme+CD4+ or CD8+ $\mathrm{T}$ cells as a parameter representative of effector immune responses. Similarly, we analyzed intratumoral concentration of CD4+CD25+FoxP3+ Treg as a parameter representative for regulatory circuits. Strikingly, protective effects induced by the different protocols of cancer vaccination were related and dependent on increasing number of tumor infiltrating CD4+granzyme+ $\mathrm{T}$ cells and decreasing concentration of Treg. Whether the effector/ regulatory ratio can be further exploited to assess the efficacy of a cancer vaccine-induced immune response needs to be analyzed in future studies.

Notwithstanding the clear protective efficacy of peptidepulsed DC vaccination, this protocol was not able to provide abrogation of tumor growth in $100 \%$ of treated mice. This prompted us to test an alternative immunotherapy based on IL-10 counteraction. This choice derives from our previous observation related to the presence within tumors of IL-10-secreting Treg able to strongly impair anti-tumor immune response [21]. Since presence of both IL-10 and IL-10-secreting Treg was demonstrated in B16F10 melanoma [our data and 24], we explored the possibility to counteract the effects of intratumoral IL-10 to unleash protective effector responses. In fact, the administration of a neutralizing anti-IL-10 mAb exerted protective effects similar to that demonstrated by peptide-pulsed DC vaccination, inducing intratumoral recruitment of $\mathrm{CD} 4+$ granzyme+ $\mathrm{T}$ cells and deplenishing of CD4+CD25+FoxP3+ Treg. These effects were not specific for B16F10 melanoma and they could be replicated in the unrelated cancer model of ALCL. More importantly, when peptide-pulsed DC vaccination and IL-10 blockade were applied in a combinatorial protocol, complete abrogation of tumor growth was achieved in $100 \%$ of treated mice.

\section{Conclusions}

Taken together, our data show that, in order to improve vaccine efficacy, comparative experimental testing of the relative protective effects of different protocols of vaccination should be performed before translating the immunotherapy to humans. The usage of IL-10 blockade represents a useful strategy for successful treatment of cancer in preclinical settings. These findings encourage the exploitation of this strategy in human settings.

\section{Additional files}

Additional file 1: Includes the Supplementary Figure 1 and the Supplementary Figure 2. 


\section{Competing interests}

The authors have no competing interests to disclosure.

\section{Author's contributions}

KF performed in vivo and in vitro experiments and drafted the manuscript, MR carried out immunization based on IL-10 neutralization in ALCL tumor model, BF performed in vivo and in vitro experiments, PA and FD carried outflow cytometric analysis, CG, FF and TS participated in experiments performed with plasmids, PM performed in vivo and in vitro experiments, SM performed tumor implantation, ME synthesized peptides, DPR carried out immunohistochemical analysis and participated in writing the paper, IG participated in designing the experimental flow chart and supervised the results, FG participated in designing the experimental flow chart, supervised the results and wrote the paper. All authors read and approved the final manuscript.

\section{Acknowledgements}

This work was supported by a grant from Compagnia di San Paolo entitled "Immunoterapia anti-tumorale: analisi d'efficacia dei principali protocolli tradizionali d'immunizzazione e validazione dell'efficacia terapeutica dell'inibizione dell'interleuchina 10 nel trattamento del melanoma", by a PRIN grant from MIUR entitled "Immunoterapia anti-tumorale operata attraverso l'inibizione dei circuiti regolatori citochino-dipendenti" and by Genovax srl through a IMMONC grant from Regione Piemonte entitled "Approcci innovativi per l'attivazione dell'immunità verso i tumori".

\section{Author details}

${ }^{1}$ Centre of Excellence for Biomedical Research, University of Genoa, Viale Benedetto XV n. 7, 16132, Genoa, Italy. ${ }^{2}$ IRCCS Azienda Ospedaliero Universitaria San Martino IST, Genoa, Italy. ${ }^{3}$ Department of Pathology and Center for Experimental Research and Medical Studies (CeRMS), University of Turin, Turin, Italy. ${ }^{4}$ Department of Clinical and Experimental Medicine, Second University of Naples, c/o II Policlinico, Naples, Italy. ${ }^{5}$ Department of Internal Medicine, University of Genoa, Genoa, Italy.

\section{Received: 21 December 2012 Accepted: 8 May 2013}

Published: 12 May 2013

\section{References}

1. Kwek SS, Cha E, Fong L: Unmasking the immune recognition of prostate cancer with CTLA4 blockade. Nat Rev Cancer 2012, 12:289-297.

2. Kantoff PW, Higano CS, Shore ND, Berger ER, Small EJ, Penson DF, Redfern CH, Ferrari AC, Dreicer R, Sims RB, Xu Y, Frohlich MW, Schellhammer PF: Sipuleucel-T immunotherapy for castration-resistant prostate cancer. N Engl J Med 2010, 363:411-422.

3. Farolfi A, Ridolfi L, Guidoboni M, Nicoletti SVL, Piciucchi S, Valmorri L, Costantini M, Scarpi E, Amadori D, Ridolfi R: Ipilimumab in advanced melanoma: reports of long-lasting responses. Melanoma Res 2012, 22:263-270.

4. Parmiani G, Castelli C, Dalerba P, Mortarini R, Rivoltini L, Marincola FM, Anichini A: Cancer immunotherapy with peptide-based vaccines: what have we achieved? Where are we going? J Natl Cancer Inst 2002, 94(Suppl 11):805-818.

5. Kirkwood JM, Butterfield LH, Tarhini AA, Zarour H, Kalinski P, Ferrone S: Immunotherapy of cancer in 2012. CA Cancer J Clin 2012, 62(Suppl 5):309-335.

6. Stan R, Wolchok JD, Cohen AD: DNA vaccines against cancer. Hematol Oncol Clin North Am 2006, 20:613-636.

7. Borghaei H, Smith MR, Campbell KS: Immunotherapy of cancer. Eur J Pharmacol 2009, 625:41-54.

8. Cheever MA, Allison JP, Ferris AS, Finn OJ, Hastings BM, Hecht TT, Mellman I, Prindiville SA, Viner JL, Weiner LM, Matrisian LM: The prioritization of cancer antigens: a national cancer institute pilot project for the acceleration of translational research. Clin Cancer Res 2009, 15:5323-5337.

9. Hoos A, Britten C: The immuno-oncology framework. Enabling a new era of cancer therapy. Oncoimmunology 2012, 1(Suppl 3):334-339.

10. Sabat R: IL-10 family of cytokines. Cytokine Growth Factor Rev 2010, 21:315-324.

11. Sato T, McCue P, Masuoka K, Salwen S, Lattime EC, Mastrangelo MJ, Berd D: Interleukin 10 production by human melanoma. Clin Cancer Res 1996, 2:1383-1390.
12. Liu X, Li J, Zhang J: STAT3-Decoy ODN inhibits cytokine autocrine of murine tumor cells. Cell Mol Immunol 2007, 4(Suppl 4):309-313.

13. Mosser DM, Zhang X: Interleukin-10: new perspectives on an old cytokine. Immunol Rev 2008, 226:205-218.

14. Hamidullah, Changkija B, Konwar R: Role of interleukin-10 in breast cancer. Breast Cancer Res Treat 2012, 133:11-21.

15. Alas S, Emmanouilides C, Bonavida B: Inhibition of interleukin 10 by rituximab results in down-regulation of $\mathrm{Bcl}-2$ and sensitization of $\mathrm{B}$-cell non-Hodgkin's lymphoma to apoptosis. Clin Cancer Res 2001, 7:709-723.

16. Fitzgerald KA, O'Neill LAJ, Gearing AJH, Callard RE: The cytokine factsbook. 2nd edition. London: Academic; 2001.

17. Haddad JJ, Saade' NE, Safieh-Garabedian B: Interleukin-10 and the regulation of mitogen-activated protein kinases: are these signalling modules targets for the anti-inflammatory action of this cytokine? Cell Signal 2003, 15:255-267.

18. Fluckiger AC, Garrone P, Durand I, Galizzi JP, Banchereau J: Interleukin 10 (IL-10) upregulates functional high affinity IL-2 receptors on normal and leukemic B lymphocytes. J Exp Med 1993, 178:1473-1481.

19. Hall BM, Verma ND, Tran GT, Hodgkinson SJ: Distinct regulatory CD4+T cell subsets; differences between naïve and antigen specific T regulatory cells. Curr Opin Immunol 2011, 23:641-647.

20. Filaci G, Fravega M, Negrini S, Procopio F, Fenoglio D, Rizzi M, Brenci S, Contini P, Olive D, Ghio M, Setti M, Accolla RS, Puppo F, Indiveri F: Nonantigen specific CD8+ T suppressor lymphocytes originate from CD8+CD28- T cells and inhibit both T-cell proliferation and CTL function. Hum Immunol 2004, 65:142-156.

21. Filaci G, Fenoglio D, Fravega M, Ansaldo G, Borgonovo G, Traverso P, Villaggio B, Ferrera A, Kunkl A, Rizzi M, Ferrera F, Balestra P, Ghio M, Contini P, Setti M, Olive D, Azzarone B, Carmignani G, Ravetti JL, Torre G, Indiveri F: CD8+CD28- T regulatory lymphocytes inhibiting $T$ cell proliferative and cytotoxic functions infiltrate humancancers. J Immunol 2007, 179:4323-4334.

22. Kriiger-Krasagakes S, Krasagakis K, Garbe C, Schmitt E, Hiuls C, Blankensteinl $\mathrm{T}$, Diamantstein T: Expression of interleukin 10 in human melanoma. Br J Cancer 1994, 70:1182-1185.

23. Gastl GA, Abrams JS, Nanus DM, Oosterkamp R, Silver J, Liu F, Chen M, Albino AP, Bander NH: Interleukin-10 production by human carcinoma cell lines and its relationship to interleukin- 6 expression. Int J Cancer 1993, 55(Suppl 1):96-101.

24. Bouabe H, Liu Y, Moser M, Boösl MR, Heesemann J: Novel highly sensitive IL$10-\beta$-lactamase reporter mouse reveals cells of the innate immune system as a substantial source of IL-10 in vivo. J Immunol 2011, 187:3165-3176.

25. Halak BK, Maguire HC Jr, Lattime EC: Tumor-induced interleukin-10 inhibits type 1 immune responses directed at atumor antigen as well as a nontumor antigen present at the tumor site. Cancer Res 1999, 59:911-917.

26. Vicari AP, Chiodoni C, Vaure C, Aït-Yahia S, Dercamp C, Matsos F, Reynard O, Taverne C, Merle P, Colombo MP, O'Garra A, Trinchieri G, Caux C: Reversal of tumor-induced dendritic cell paralysis by CpG immunostimulatory oligonucleotide and anti-interleukin 10 receptor antibody. J Exp Med 2002, 196(Suppl 4):541-549.

27. Overwijk WW, Restifo NP: B16 as a mouse model for human melanoma. In Curr Protoc Immunol. CHAPTER: Unit-201st edition. John Wiley and Sons Inc; 2001. doi:10.1002/0471142735.im2001s39.

28. Esquivel F, Yewdell J, Bennink J: RMA/S cells present endogenously synthesized cytosolic proteins to class I-restricted cytotoxicT lymphocytes. J Exp Med 1992, 175:163-168.

29. Chiarle R, Martinengo C, Mastini C, Ambrogio C, D'Escamard V, Forni G, Inghirami $\mathrm{G}$ : The anaplastic lymphoma kinase is an effective oncoantigen for lymphoma vaccination. Nat Med 2008, 14(Suppl 6):676-680.

30. Wellings DA, Atherton E: Standard Fmoc protocols. Methods Enzymol 1997, 289:44-67.

31. Klein C, Bueler H, Mulligan RC: Comparative analysis of genetically modified dendritic cells and tumor cells as therapeutic cancer vaccines. J Exp Med 2000, 191:1699-1708.

32. Di Giacomo AM, Danielli R, Guidoboni M, Calabrò L, Carlucci D, Miracco C, Volterrani L, Mazzei MA, Biagioli M, Altomonte M, Maio M: Therapeutic efficacy of ipilimumab, an anti-CTLA-4 monoclonal antibody, in patients with metastatic melanoma unresponsive to prior systemic treatments: clinical and immunological evidence from three patient cases. Cancer Immunol Immunother 2009, 58:1297-1306.

33. Seo N, Hayakawa S, Takigawa M, Tokura Y: Interleukin-10 expressed at early tumour sites induces subsequent generation ofCD4+ T-regulatory 
cells and systemic collapse of antitumour immunity. Immunology 2001, 103:449-457.

34. Sheikh NA, Petrylak D, Kantoff PW, Dela Rosa C, Stewart FP, Kuan LY, Whitmore JB, Trager JB, Poehlein CH, Frohlich MW, Urdal DL: Sipuleucel-T immune parameters correlate with survival: an analysis of the randomized phase 3 clinical trials in men with castration-resistant prostate cancer. Cancer Immunol Immunother 2012:PMID: 22865266 [Epub ahead of print].

35. Yang JC: Melanoma vaccines. Cancer J 2011, 17:277-282.

36. Bergman PJ, McKnight J, Novosad A, Sarah Charney S, Farrelly J, Craft D, Wulderk M, Jeffers Y, Sadelain M, Hohenhaus AE, Segal N, Gregor P, Engelhorn M, Riviere I, Houghton AN, Wolchok JD: Long-term survival of dogs with advanced malignant melanoma after DNA vaccination with xenogeneic human tyrosinase: a phase I trial. Clin Cancer Res 2003, 9:1284-1290.

37. Gold JS, Ferrone CR, JA G-P o, Hawkins WG, Dyall R, Engelhorn ME, Wolchok $J \mathrm{D}$, Lewis $\mathrm{J}$, Houghton AN: A single heteroclitic epitope determines cancer immunity after xenogeneic DNA immunization against a tumor differentiation antigen. J Immunol 2003, 170:5188-5194.

38. Iero M, Filipazzi P, Castelli C, Belli F, Valdagni R, Parmiani G, Patuzzo R, Santinami M, Rivoltini L: Modified peptides in anti-cancer vaccines: are we eventuallyimproving anti-tumour immunity? Cancer Immunol Immunother 2009, 58:1159-1167.

39. Filipazzi P, Pilla L, Mariani L, Patuzzo R, Castelli C, Camisaschi C, Maurichi A, Cova A, Rigamonti G, Giardino F, Di Florio A, Asioli M, Frati P, Sovena G, Squarcina P, Maio M, Danielli R, Chiarion-Sileni V, Villa A, Lombardo C, Tragni G, Santinami M, Parmiani G, Rivoltini L: Limited induction of tumor crossreactive $T$ cells without a measurable clinical benefit in early melanoma patients vaccinated with human leukocyte antigen class I-modified peptides. Clin Cancer Res 2012, 18(23):6485-6496.

40. Moser M, Leo O: Key concepts in immunology. Vaccine 2010, 28S:C2-C13.

41. Zepp F: Principles of vaccine design - Lessons from nature. Vaccine 2010 28S:C14-C24.

42. Vergati M, Intrivici C, Huen N-Y, Schlom J, Tsang KY: Strategies for cancer vaccine development. J Biomed Biotechnol 2010. doi:10.1155/2010/596432

43. Dubensky TW Jr, Reed SG: Adjuvants for cancer vaccines. Semin Immunol 2010, 22:155-161.

44. Church SE, Jensen SM, Twitty CG, Bahjat K, Hu HM, Urba WJ, Fox BA: Multiple vaccinations friend or foe. Cancer J 2011, 17:379-396.

45. Fujii H, Arakawa A, Kitoh A, Miyara M, Kato M, Kore-eda S, Sakaguchi S, Miyachi Y, Tanioka M, Ono M: Perturbations of both nonregulatory and regulatory FOXP3+ T cells in patients with malignant melanoma. Br J Dermatol 2011, 164:1052-1060.

46. Sakaguchi S, Yamaguchi T, Nomura T, Ono M: Regulatory T cells and immune tolerance. Cell 2008, 133:775-787.

47. Sakaguchi S, Wing K, Yamaguchi T: Dynamics of peripheral tolerance and immune regulation mediated by Treg. Eur J Immunol 2009, 39:2331-2336.

doi:10.1186/1479-5876-11-120

Cite this article as: Kalli et al:: Comparative analysis of cancer vaccine settings for the selection of an effective protocol in mice. Journal of Translational Medicine 2013 11:120.

\section{Submit your next manuscript to BioMed Central and take full advantage of:}

- Convenient online submission

- Thorough peer review

- No space constraints or color figure charges

- Immediate publication on acceptance

- Inclusion in PubMed, CAS, Scopus and Google Scholar

- Research which is freely available for redistribution 